\title{
Depressed gastric-type adenoma in nonatrophic gastric mucosa without Helicobacter pylori infection
}

Gastric adenoma is a benign epithelial tumor and is frequently observed as an elevated rather than a depressed lesion and in Helicobacter pylori-infected mucosa [1]. We describe a rare case of depressed gastric-type adenoma in nonatrophic gastric mucosa without $H$. pylori infection.

A 59-year-old man was referred to our hospital for further examination and treatment of gastric neoplasia. Endoscopy revealed a whitish depressed lesion, $10 \mathrm{~mm}$ in diameter, in the greater curvature of the lower gastric body ( $\triangleright$ Fig. 1 ). Atrophy and intestinal metaplasia were not observed in the background gastric mucosa ( Fig.2). Furthermore, serum $H$. pylori antibody, serum pepsinogen, and urea breath tests were all negative, indicating that the gastric mucosa was not infected by $H$. pylori.

Magnifying endoscopy using narrowband imaging showed an irregular microsurface pattern with round and oval pits and a slightly irregular microvascular architecture with discordant looped vessels ( $\triangleright$ Fig. $\mathbf{3}$ ) in the lesion. In accordance with the vascular pattern, surface pattern (VS) classification system [2], these findings were categorized as an irregular microsurface pattern and an irregular microvascular pattern with a demarca-

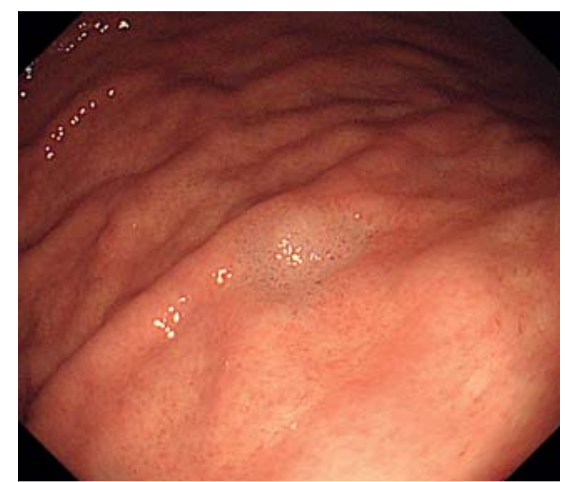

- Fig. 1 Endoscopic image showing a whitish depressed lesion, $10 \mathrm{~mm}$ in diameter, in the greater curvature of the lower gastric body. tion line, which were indications of malignancy. Thus, although the biopsy specimen showed adenoma (\$ Fig.4), endoscopy revealed malignant findings. Endoscopic submucosal resection was performed for histologic evaluation ( Video 1).

Histologically, the tumor cells showed gastric-type adenoma. Immunohistochemically, the tumor cells were positive for mucin (MUC) 5AC and MUC6 but negative for MUC2 and CD10 ( $\mathbf{F i g . 5} \mathbf{a}-\mathbf{d}$ ).

There are a few reports on depressedtype gastric adenomas in $\mathrm{H}$. pylori-noninfected gastric mucosa, and some reports state that some gastric adenomas may progress to adenocarcinoma [3]. There is no consensus about the treatment for gastric adenoma in $H$. pylorinoninfected gastric mucosa. However,

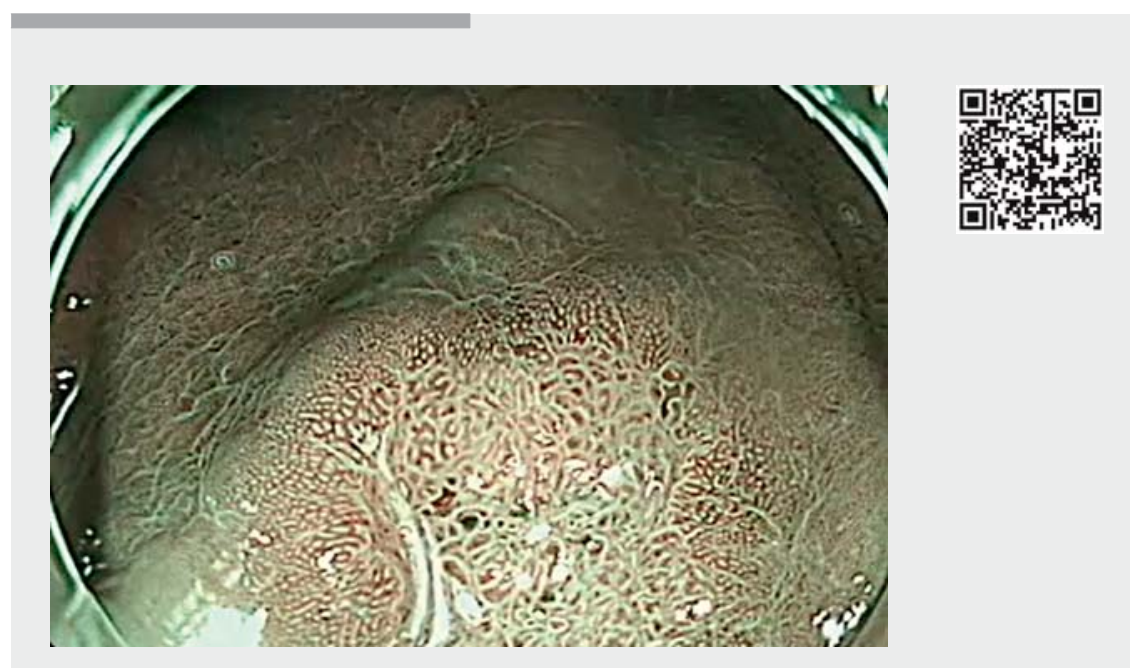

Video 1 Depressed gastric-type adenoma in nonatrophic gastric mucosa without Helicobacter pylori infection: endoscopic submucosal resection performed for histologic evaluation.
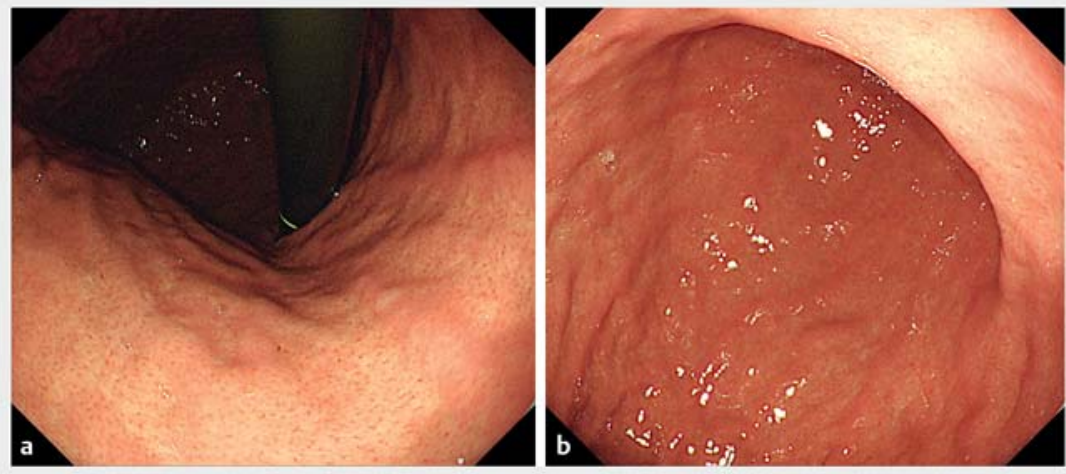

Fig. 2 a, b Atrophy and intestinal metaplasia were not observed in the background gastric mucosa. 


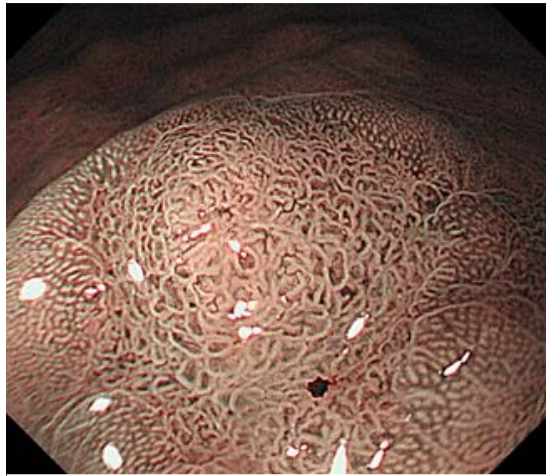

- Fig. 3 Magnifying endoscopy with narrow-band imaging showed an irregular microsurface pattern with round and oval pits and slightly irregular microvascular architecture with discordant looped vessels.

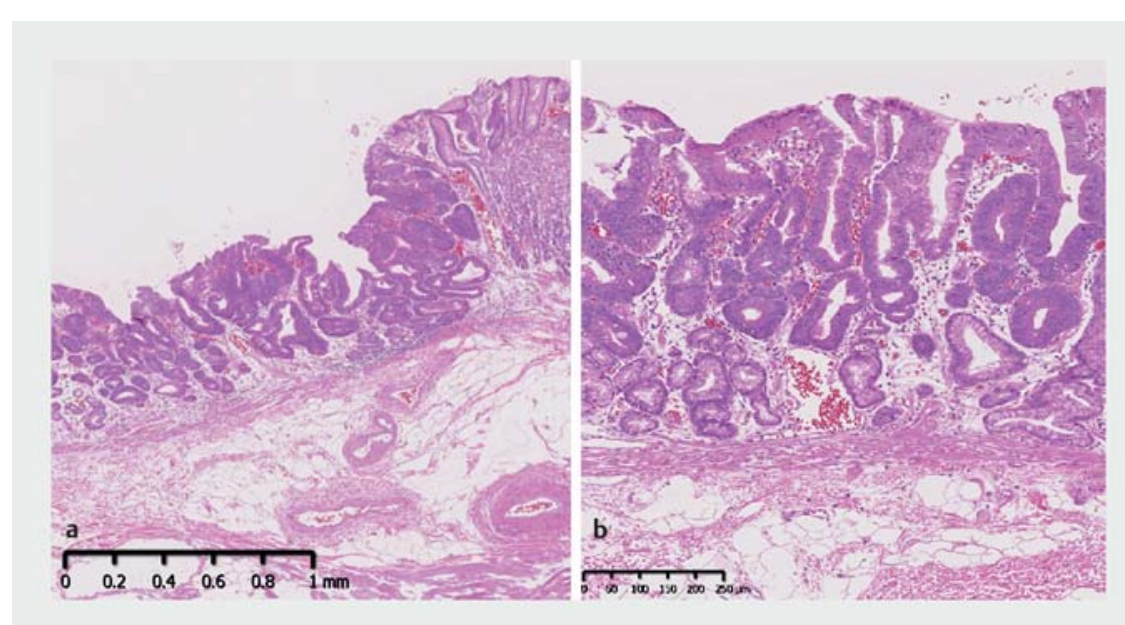

- Fig. 4 a, b Histological examination showed gastric-type adenoma.

we recommend that endoscopic submucosal dissection as a total biopsy is also necessary. It is important to accumulate further cases to clarify the characteristics of gastric adenomas in $\mathrm{H}$. pylori-noninfected gastric mucosa.

Endoscopy_UCTN_Code_CCL_1AB_2AD_3AB

Competing interests

The authors declare no conflicts of interest for this article.

The authors

Keiichiro Nishihara ${ }^{1}$, Yasuhiro Oono ${ }^{1}$, Takeshi Kuwata ${ }^{2}$, Hiroaki Ikematsu', Tomonori Yano ${ }^{1}$

1 Department of Gastroenterology and Endoscopy, National Cancer Center Hospital East, Kashiwa, Chiba, Japan

2 Department of Pathology and Clinical Laboratories, National Cancer Center Hospital East, Kashiwa, Chiba, Japan

Corresponding author

\section{Keiichiro Nishihara, MD}

Department of Gastroenterology and Endoscopy, National Cancer Center Hospital East, 6-5-1, Kashiwanoha, Kashiwa, Chiba 277-8577, Japan

Fax: +81-4-71346928

kenishih@east.ncc.go.jp 


\section{References}

[1] Tamai N, Kaise M, Nakayoshi T et al. Clinical and endoscopic characterization of depressed gastric adenoma. Endoscopy 2006; 38: 391-394

[2] Yao K, Anagnostopoulos GK, Ragunath K. Magnifying endoscopy for diagnosing and delineating early gastric cancer. Endoscopy 2009; 41: $462-467$

[3] Taniyama D, Taniyama K, Kuraoka K et al. Long-term follow-up study of gastric adenoma; tumor-associated macrophages are associated to carcinoma development in gastric adenoma. Gastric Cancer 2017; 20: 929-939
Bibliography

DOI https://doi.org/10.1055/a-0866-9051

Published online: 25.3.2019

Endoscopy 2019; 51: E138-E140

(c) Georg Thieme Verlag KG

Stuttgart · New York

ISSN 0013-726X

\section{ENDOSCOPY E-VIDEOS}

https://eref.thieme.de/e-videos

口居回 Endoscopy E-Videos is a free ry access online section, reporting 靣船: on interesting cases and new techniques in gastroenterological endoscopy. All papers include a high quality video and all contributions are freely accessible online.

This section has its own submission website at

https://mc.manuscriptcentral.com/e-videos 